\title{
Anomalous flexor digitorum superficialis muscle transposition for vascular coverage of the median nerve in recurrent carpal tunnel syndrome
}

\author{
Michael W Neumeister MD, Arian Mowlavi MD, Robert C Russell MD, Bradon J Wilhelmi MD
}

\begin{abstract}
MW Neumeister, A Mowlavi, RC Russell, BJ Wilhelmi. Anomalous flexor digitorum superficialis muscle transposition for vascular coverage of the median nerve in recurrent carpal tunnel syndrome. Can J Plast Surg 2005;13(1):27-30.

Recurrent carpal tunnel syndrome is uncommon yet troublesome. Significant adhesions and scarring around the median nerve can render it relatively ischemic. A number of vascular flaps have been described to provide vascular coverage in attempts to decrease further cicatricial adhesions and to improve local blood supply around the median nerve. A rare case of an anomalous muscle in the distal forearm used as tissue to provide good vascularized coverage of the median nerve that was severely scarred in its bed is reported. The anomalous muscle was distal to the flexor digitorum superficialis tendon and inserted in the palmar fascia on the ulnar aspect of the hand. Referring branches from the ulnar artery provided vascular supply to the anomalous muscle. The muscle on these vascular pedicles was transposed over the median nerve, providing good, stable, unscarred coverage. The patient had an excellent result with resolution of the carpal tunnel symptoms. The redundant anomalous muscle provided a unique vascularized source for coverage of the median nerve in recurrent carpal tunnel syndrome.
\end{abstract}

\section{Transposition du flexor digitorum superficialis pour assurer la couverture vasculaire du nerf médian dans une récidive de syndrome du tunnel carpien}

\begin{abstract}
La récidive du syndrome du tunnel carpien est un phénomène rare, mais ennuyeux. La formation d'adhésions et de tissu cicatriciel importants autour du nerf médian peut rendre ce dernier relativement ischémique. Un certain nombre de lambeaux ont été décrits pour assurer la couverture vasculaire et réduire les adhésions cicatricielles et améliorer ainsi l'irrigation sanguine locale autour du nerf médian. On décrit ici un cas rare de transposition d'un muscle de l'avant-bras distal pour fournir une bonne vascularisation du tendon médian gravement cicatrisé. Le muscle était situé à la portion distale du tendon du flexor digitorum superficialis et inséré dans l'aponévrose palmaire de la portion cubitale de la main. Les branches de l'artère cubitale ont fourni l'irrigation vasculaire vers le muscle greffé. Le muscle chevauchant ces pédoncules vasculaires a été transposé sur le nerf médian, lui offrant une bonne couverture, stable et non cicatrisée. La patiente a obtenu d'excellents résultats avec résolution de ses symptômes. La greffe musculaire a constitué une source hors pair de vascularisation du nerf médian dans ce cas de récidive de syndrome du tunnel carpien.
\end{abstract}

Key Words: Anomalous muscle; Carpal tunnel syndrome; Ischemia; Recurrent

\begin{abstract}
Carpal tunnel syndrome (CTS) recurrences have been - reported in $0.3 \%$ to $19 \%$ of patients following primary release of the transverse carpal ligament (TCL) (1-3). Up to $12 \%$ of these patients will require operative re-exploration and neurolysis of the median nerve $(4,5)$. The most common causes of recurrence include incomplete release of the TCL $(6,7)$, scarring of the median nerve to the undersurface of the remnant carpal ligament, and recurrent tenosynovitis or indiscriminate scarring in the carpal tunnel (fibrous proliferation) $(1,2)$. Persistent worsening or acute return of preoperative symptoms is suggestive of incomplete TCL release and is reported in 1\% to $33 \%$ of those undergoing open CTS release (5-9). Fibrous proliferation represents intracarpal scar tissue formation and subsequent adhesion entrapment of the median nerve $(7,8,10,11)$. This scarring occurs in $0.5 \%$ to $1.1 \%$ of patients and typically presents one year following surgery (12-14). Inflammatory tenosynovitis occurs in $0.1 \%$ to $0.7 \%$ of patients and is associated with various systemic inflammatory diseases, metabolic disorders or infectious etiologies $(3,15-25)$. Most recurrences due to tenosynovitis occur within months of the primary release $(1,2)$.
\end{abstract}

The median nerve that has become encased in a sclerosing cicatricial bed often develops ischemic changes and subsequent fibrosis within the nerve $(8,14,26)$. A repeated attempt of simple neurolysis only portends a poor prognosis. More extensive local muscle flap transfers have been advocated to re-establish and/or ensure unobstructed vascular coverage over the median nerve in an attempt to attenuate further scarring. The pronator quadratus $(7,25)$, abductor digiti minimi $(7,25,27-31)$, lumbricals $(25)$ and palmaris brevis $(25,32)$ have all been employed to supply coverage for a scar-laden median nerve without the carpal tunnel. We present a unique case of an anomalous muscle transposition flap, involving an aberrant slip of flexor digitorum superficialis (FDS) muscle to provide enhanced vascularized coverage of a compromised median nerve within the carpal tunnel.

\section{CASE PRESENTATION}

A 30-year-old woman who had undergone a previous open release of her TCL and release of Guyon's canal one year prior presented with recurrent symptoms of CTS. She complained of numbness and tingling in her thumb, index and ring finger.

Southern Illinois University, Institute for Plastic and Reconstructive Surgery, Springfield, Illinois, USA

Correspondence: Dr Michael W Neumeister, Southern Illinois University School of Medicine, 747 North Rutledge Street, PO Box 19653,

Springfield, Illinois 62794-9653, USA. Telephone 217-545-7018, fax 217-545-2588, e-mail mneumeister@siumed.edu 


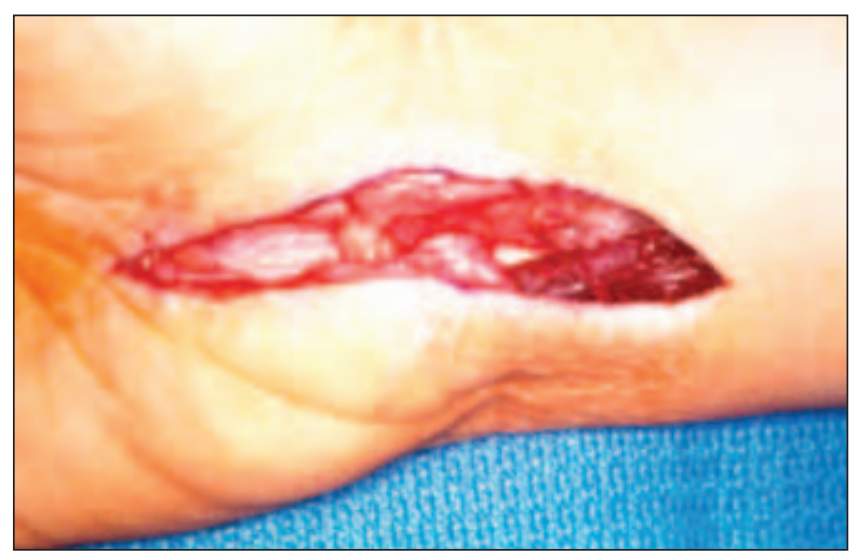

Figure 1) An anomalous slip of the flexor digitorum sublimis muscle lies ulnar to the carpal tunnel. The muscle ends blindly in the palmar fascia. It originates solely from the flexor digitorum sublimis muscle belly joint proximal to the incision

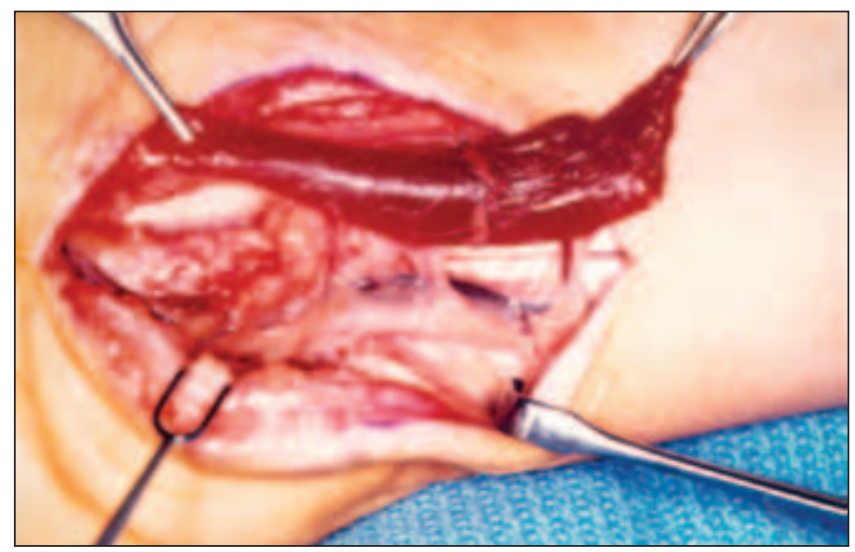

Figure 2) The anomalous muscle belly has three distinct vascular pedicles arising from the ulnar artery

The symptoms awakened her at night and progressively worsened. Her grip strength was subjectively decreased. The examination of the hand revealed a Tinel's sign and positive provocative compression test (Phalen's) over the previous scar at the carpal tunnel. A mass was also noted in the distal forearm, proximal and ulnar to the previous scar. This mass was soft, nonadherent to the overlying skin, nonpulsatile and minimally compressible. Conservative management consisted of applying a dorsal ulnar splint to the wrist. The nerve conduction studies indicated recurrent, severe compression of the median nerve within the carpal tunnel. Despite splinting for eight weeks, the symptoms progressed, mandating surgical decompression and external neurolysis. Under regional (Bier block) anesthesia, an incision was made along the previous scar in the palm. This incision was extended in a proximal ulnar direction toward the noted forearm mass. An external neurolysis of the median nerve under microscopic visualization released the encasing scar. The severity of the scar tissue around the nerve and within the carpal tunnel bed warranted vascular coverage of the median nerve. A palmaris brevis turnover flap was contemplated to provide vascular coverage of the median nerve on exploration of the distal forearm; however, the palpable mass proved to be an anomalous muscle. A large, anomalous slip of the FDS

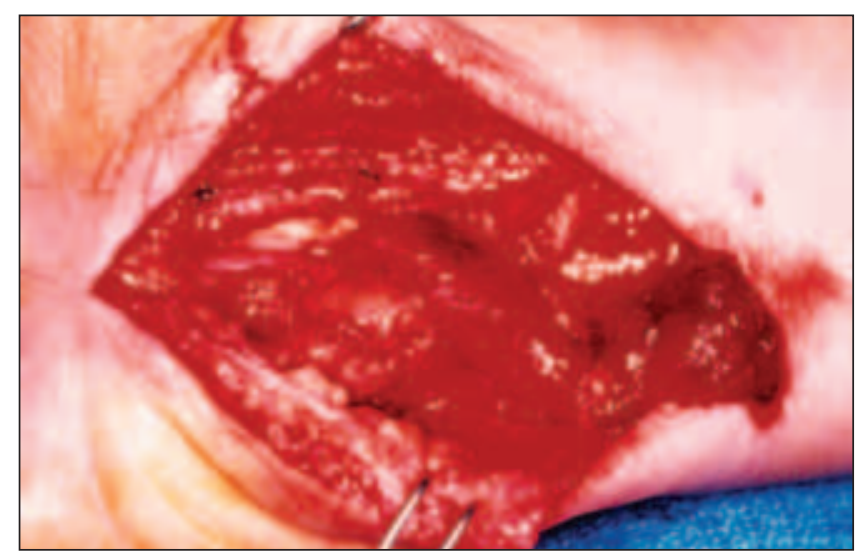

Figure 3) The transposed muscle belly rests without tension or compromise over the median nerve

muscle extended from the primary FDS muscle to the pisiform base and into the palm. The muscle travelled over the hypothenar region and ended blindly in the palmar fascia (Figure 1). There was no obvious nerve impingement by this muscle. It was elected to substitute this muscle for the planned palmaris brevis turnover flap for vascularized coverage of the median nerve. The muscle was transected proximally and distally and transposed based on three distinct vascular pedicles originating from the ulnar artery to cover the median nerve in the carpal tunnel (Figure 2). The muscle remained viable following transposition and was fixed in place with 4-0 Vicryl sutures (Figure 3). A butterfly drain was placed in the carpal tunnel and the skin was reapproximated using 5-0 nylon sutures. The patient's wrist and hand were splinted in the safe position. Range of motion exercises were initiated 10 days postoperatively. Two weeks following the operation, the sutures were removed and the patient was allowed to begin aggressive finger and wrist rehabilitation. The sensation in the radial three digits returned to normal (two-point discrimination less than $5 \mathrm{~mm}$ ) and the patient remained asymptomatic. Three months later, however, she complained of occasional numbness in the ring and small finger of her hand. Provocative tests were negative and intrinsic muscle function normal. Over the next four months, the patient developed a Tinel's sign over the proximal aspect of the Guyon's canal. Electromyelography studies revealed irritation and slowing of conduction in the ulnar nerve in Guyon's canal. Despite splinting, the symptoms and findings persisted. During surgical decompression of the ulnar nerve at the wrist, the patient's muscle transposition was located and noted to be properly located over the median nerve and not grossly impinging on the ulnar nerve. Additionally, an external neurolysis of the ulnar nerve was performed after identifying a small amount of scar tissue over this nerve. At four years follow-up, she had no recurrence of her median nerve symptoms and had full function of the hand, although she occasionally experienced mild cold sensitivity of her two ulnar fingers.

\section{DISCUSSION}

Several manoeuvres have been recommended to minimize the development of excessive intracarpal tunnel scarring related to fibrous proliferation to prevent recurrent nerve entrapment following primary release $(1,2)$. Release of the tourniquet, 
meticulous hemostasis before wound closure and placement of suction drainage for three to four days have been emphasized to decrease hematoma and subsequent fibrosis $(8,25)$. Wound closure with skin sutures only and immobilization of the wrist in slight palmar flexion over one to three weeks using a palmar short arm splint has also been advocated to reduce deep adhesions $(8,25)$. The flexed wrist positioning was suggested to retract the median nerve away from the acutely healing subcutaneous tissue. In contrast to splinting protocols, aggressive hand therapy programs with early motion may in fact be more beneficial by preventing the formation of restrictive adhesions between the median nerve and the flexor tendons or the undersurface of the radial aspect of the carpal ligament (1).

The definitive diagnosis of scarring secondary to fibrous proliferation in recurrent CTS is typically made at the time of re-exploration. However, the timing of recurrence can often aid in preoperative diagnosis. The usual evolution of symptoms follows at least one year after primary repair. Recurrences related to inadequate or incomplete TCL release are not usually recurrences at all. In fact, the symptoms may never resolve following surgery or may become worse. Tenosynovitis is infrequently associated with recurrent CTS and is often associated with systemic symptoms. The tenosynovitis progresses over months to years.

Operative management options of fibrous proliferation have included scar debridement, epineurolysis, internal neurolysis, application of barrier materials such as encircling silastic or vein graft, as well as various local muscle or fat pad flaps $(2,8,13,14,33,34)$. Local flaps are intended to provide not only physical padding but also increased vascularization to compromised nerve vasculature. Primary release of the compressed median nerve and concomitant external neurolysis may render the nerve relatively ischemic. Furthermore, the carpal tunnel bed is a poor recipient site for the already vascularly compromised segment of median nerve. A vascularized muscle flap transposition may, therefore, minimize further ischemic axonal degeneration and adhesions to the surrounding tissue (32).

In 1977, Milward et al (28) described the first muscle flap transposition using a proximally based abductor digiti minimi muscle flap. The abductor digiti minimi provides excellent distal nerve coverage $(13,28)$. Alternatively, the lumbricals have been utilized for distal coverage but were limited by their small size (26). The pronator quadratus provides adequate proximal

\section{REFERENCES}

1. Botte MJ, von Schroeder HP, Abrams RA, Gellman H. Recurrent carpal tunnel syndrome. Hand Clin 1996;12:731-43.

2. Hunter JM. Recurrent carpal tunnel syndrome, epineural fibrous fixation, and traction neuropathy. Hand Clin 1991;7:491-504.

3. Hulsizer DL, Staebler MP, Weiss AP, Akelman E. The results of revision carpal tunnel release following previous open versus endoscopic surgery. J Hand Surg [Am] 1998;23:865-9.

4. Kulick MI, Gordillo G, Javidi T, Kilgore ES Jr, Newmayer WL III. Long-term analysis of patients having surgical treatment for carpal tunnel syndrome. J Hand Surg [Am] 1986;11:59-66.

5. MacDonald RI, Lichtman DM, Hanlon JJ, Wilson JN. Complications of surgical release for carpal tunnel syndrome. J Hand Surg [Am] 1978;3:70-6.

6. De Smet L. Recurrent carpal tunnel syndrome. Clinical testing indicating incomplete section of the flexor retinaculum. J Hand Surg [Br] 1993;18:189.

7. Mackinnon SE, Dellon AL. Painful sequelae of peripheral nerve injury. In: Mackinnon SE, Dellon AL, eds. Surgery of the Peripheral Nerve. New York: Meriscola, 1988:455-519.

8. Langloh ND, Linscheid RL. Recurrent and unrelieved carpaltunnel syndrome. Clin Orthop 1972;83:41-7. coverage (25). More recently, the palmaris brevis turnover flap has been employed to provide a thin yet broad coverage of the median nerve $(35,36)$. This flap is mostly comprised of fat but usually includes varying amounts of muscle fibres. Other less commonly described flaps include the hypothenar fat pad $(25,37,38)$, a reverse radial artery fascial flap (39), a dermal-fat graft (41) and a synovial flap (41).

In the present case, the utilization of a clinically asymptomatic anomalous FDS muscle transposition for providing muscular coverage of the median nerve in a repeat median nerve release at the carpal tunnel is presented. Most anatomical variations of the FDS have little clinical significance. Interestingly, anomalous FDS muscles have been implicated as rare causes of primary CTS $(42,43)$. FDS anomaly variations have been described by a classification system comprising types I to V (44). Types I to IV involve variations in shape and/or attachment. Type $\mathrm{V}$ refers to a true anomaly with a separate split muscle belly and independent attachments usually located in the distal forearm. Our case involved a type $\mathrm{V}$ anomaly. A separate slip had left the main muscle body in the distal forearm. The anomalous muscle travelled beside the ulnar artery and nerve to course adjacent to the pisiform bone. The anomaly ended in the fascia of the palm just beyond the pisiform over the hypothenar muscles. Multiple vascularity pedicles from the ulnar artery provided a separate blood supply to this muscle slip. In fact, tendons were noted to service each of the fingers. The anomalous slip, therefore, had no function. This provided an opportunity to transpose this muscle without disturbance of other functional muscles. By releasing the muscle proximally and distally, the blood supply was preserved because the muscle was transposed to conveniently cover the median nerve. The patient has had an excellent result without any residual CTS symptoms since her revision CTS surgery.

\section{SUMMARY}

We present a review of fibrous proliferation as a common cause of CTS recurrence and its successful operative management using an anomalous FDS muscle transposition. This case stresses the necessity of thorough exploration of the surgical field during primary or revision surgery. The redundant anomalous muscle provided a unique source for local flap transposition without detriment to other local muscles or subcutaneous tissue.

9. Agee JM, McCarroll HR Jr, Tortosa RD, Berry DA, Szabo RM, Peimer CA. Endoscopic release of the carpal tunnel: A randomized prospective multicenter study. J Hand Surg [Am] 1992;17:987-95.

10. Mackinnon SE, Hudson AR, Gentili F, Kline DG, Hunter D. Peripheral nerve injection injury with steroid agents. Plast Reconstr Surg 1982;69:482-90.

11. Rose EH, Norris MS, Kowalski TA, Lucas A, Flegler EJ. Palmaris brevis turnover flap as an adjunct to internal neurolysis of the chronically scarred median nerve in recurrent carpal tunnel syndrome. J Hand Surg [Am] 1991;16:191-201.

12. Paine KW. The carpal tunnel syndrome. Can J Surg 1963;41:446-9.

13. Phalen GS. The carpal-tunnel syndrome. Seventeen years experience in diagnosis and treatment of six hundred fifty-four hands. J Bone Joint Surg Am 1966;48:211-28.

14. Phalen GS. The carpal-tunnel syndrome. Clinical evaluation of 598 hands. Clin Orthop 1972;83:29-40.

15. Calderon MS, Chung KC.Case report. Initial manifestation of gout after carpal tunnel release. Br J Plast Surg 1999;52:76-7.

16. Care SB, Lacey SH. Recurrent histoplasmosis of the wrist: A case report. J Hand Surg [Am] 1998;23:1112-4. 
17. Chary-Valckenaere I, Kessler M, Mainard D, et al. Amyloid and non-amyloid carpal tunnel syndrome in patients receiving chronic renal dialysis. J Rheumatol 1998;25:1164-70.

18. Farrell J, Bastani B. Beta 2-microglobulin amyloidosis in chronic dialysis patients: A case report and review of the literature. J Am Soc Nephrol 1997;8:509-14.

19. Berglund J, Blomberg I, Hansen BU. Lyme borreliosis in rheumatological practice: Identification of Lyme arthritis and diagnostic aspects in a Swedish county with high endemicity. Br J Rheumatol 1996;35:853-60.

20. Kim HC, Cheigh JS, David DS, et al. Long term results of subtotal parathyroidectomy in patients with end-stage renal disease. Am Surg 1994;60:641-9.

21. Koss SD, Reardon TF, Groves RJ. Recurrent carpal tunnel syndrome due to tuberculoid leprosy in an Asian immigrant. J Hand Surg [Am] 1993;18:740-2.

22. Kurer MH, Baillod RA, Madgwick JC. Musculoskeletal manifestations of amyloidosis. A review of 83 patients on haemodialysis for at least 10 years. J Bone Joint Surg Br 1991;73:271-6.

23. Kelly PJ, Karlson AG, Weed LA, Lipscomb PR. Infection of synovial tissues by mycobacteria other than Mycobacterium tuberculosis. J Bone Joint Surg Am 1967;49:1521-30.

24. Mascola JR, Rickman LS. Infectious causes of carpal tunnel syndrome: Case report and review. Rev Infect Dis 1991;13:911-7.

25. Urbaniak JR. Complications of treatment of carpal tunnel syndrome. In: Gelberman RH, ed. Operative Nerve Repair and Reconstruction. Philadelphia; JB Lippincott, 1991:967-79.

26. Wadstroem J, Nigst H. Reoperation for carpal tunnel syndrome. A retrospective analysis of forty cases. Ann Chir Main 1986;5:54-8.

27. Leslie BM, Ruby LK. Coverage of a carpal tunnel wound dehiscence with the abductor digiti minimi muscle flap. J Hand Surg [Am] 1988;13:36-9.

28. Milward TM, Stott WG, Kleinert HE. The abductor digiti minimi muscle flap. Hand 1977;9:82-5.

29. Resnick CT, Miller BW. Endoscopic carpal tunnel release using the subligamentous two-portal technique. Contemp Orthop 1991;22:269-77.

30. Wilgis EF. Local muscle flaps in the hand. Anatomy as related to reconstructive surgery. Bull Hosp Jt Dis Orthop Inst 1984;44:552-7.
31. Wilgis EF, Murphy R. The significance of longitudinal excursion in peripheral nerves. Hand Clin 1986;2:761-6.

32. Rydevik B, Lundborg G, Nordborg C. Intraneural tissue reactions induced by internal neurolysis. An experimental study on the blood-nerve barrier, connective tissues and nerve fibres of rabbit tibial nerve. Scand J Plast Reconstr Surg 1976;10:3-8.

33. Masear VR, Hayes JM, Hyde AG. An industrial cause of carpal tunnel syndrome. J Hand Surg [Am] 1986;11:222-7.

34. North ER, Kaul MP. Compression neuropathies: Median. In: Peimer CA, ed. Surgery of the Hand and Upper Extremity. New York: McGraw-Hill, 1996:1307-36.

35. Kelly MB, Bosmans L, Gault D. Use of the palmaris brevis flap for preventing recurrent median nerve compression in mucolipidosis. J Hand Surg [Br] 1999;24:300-2.

36. Rose EH. The use of the palmaris brevis flap in recurrent carpal tunnel syndrome. Hand Clin 1996;12:389-95.

37. Strickland JW, Idler RS, Lourie GM, Plancher KD. The hypothenar fat pad flap for management of recalcitrant carpal tunnel syndrome. J Hand Surg [Am] 1996;21:840-8.

38. Plancher KD, Idler RS, Lourie GM, Strickland JW. Recalcitrant carpal tunnel. The hypothenar fat pad flap. Hand Clin 1996;12:337-49.

39. Tham SK, Ireland DC, Riccio M, Morrison WA. Reverse radial artery fascial flap: A treatment for the chronically scarred median nerve in recurrent carpal tunnel syndrome. J Hand Surg [Am] 1996;21:849-54.

40. McClinton MA. The use of dermal-fat grafts. Hand Clin 1996;12:357-64.

41. Wulle C. The synovial flap as treatment of the recurrent carpal tunnel syndrome. Hand Clin 1996;12:379-88.

42. Ametewee K, Harris A, Samuel M. Acute carpal tunnel syndrome produced by anomalous flexor digitorum superficialis indicis muscle. J Hand Surg [Br] 1985;10:83-4.

43. Grant SD, Due TM. Anomalous flexor digitorum superficialis presenting as a painful palmar mass: A case report. Clin Anat 1995;8:432-3.

44. Elliot D, Khandwala AR, Kulkarni M. Anomalies of the flexor digitorum superficialis muscle. J Hand Surg [Br] 1999;24:570-4. 